\title{
IOT based system for person with physical
}

\section{disability}

\author{
Gagan \\ PG scholar, NMAMIT, Nitte, India
}

\begin{abstract}
Day by day as the technology is growing it is reducing the human effort. Home Automation/Smart home system is getting more importance as it increases the security, comfort and improves the quality of life. In this paper a smart home monitoring and alerting system for disabled person is being proposed. This system gives security, and comfort for the elderly people and person's with disability. In this proposed model intel galileo board is used to achieve monitoring of humidity and temperature, gas, smoke, motion and fire and controlling different electrical appliances like fan, heater, lights etc. If the sensor value exceeds the threshold value system should alert the user and should actuate required safety procedure. Alerting and other data are sent to user through internet. Using this system user can monitor the home from anywhere and anytime using internet compatible devices.
\end{abstract}

Keywords: Home Automation, Smart Home, Disabled, internet, Microcontroller.

\section{INTRODUCTION}

Smart home concept came to practice in $20^{\text {th }}$ century. Smart home is adopted for reason of ease, security and energy efficiency. Smart home system refers to use of computer and information technology to control home appliances. Smart home may include centralized control of HVAC (heating, ventilation and air conditioning), lighting, appliances, security locks for doors and gates and other systems to provide energy efficiency, convenience, comfort and security. Smart home for the elderly, physically handicapped and disabled can provide increased quality of life for persons who might otherwise require institutional care or caregivers. Smart home systems are gaining importance in recent years due to affordability and simplicity through smart phone and tablet connectivity. The concept of the "internet of things" has tied in closely with the popularization of home automation. Electrical devices may be connected through home network to control by a PC and may allow remote control from the internet. Smart home system will be very useful for elder people who are very important segment of life. Person with disability require assistance to do their daily routines, therefore nurses are employed to assist them. But middle aged people prefer to live independently and self-managing in their own home which gives the feeling of independence. Using smart home systems will reduce expenditure and is more beneficial than attending medical centers. This type of system with remote monitor controls and health care capability will decrease the cost of personal aid assistance at home. Smart home system can also be used to monitor environment to ensure safety and alert people when there is likely to be a dangerous situation, as for example, the elderly persons or people who have Alzheimer disease may forget switching off gas oven after cooking in kitchen and deaf people cannot hear the doorbell. Using such a system will reduce the risks mentioned above.

\section{LITERATURE SURVEY}

1) Authors proposed a home automation system for elderly and disabled person using Xbee. This system help in controlling the electric appliances using Xbee module. LED's and Monitor display is used to alert the user. The communication between remote control and the base is done with the help of RF signals.

2) Discuss about the smart home technology for independent living person with disabilities and elderly people using smart home technology. In this paper they have explained about energy saving, support for the elderly and disabled, Safety and Security, wireless sensor node and different types of sensors that can be used in home automation.

3) Presents a smart home system using ZigBee based voice controlled wireless. LabVIEW software is used for the voice recognition system. Different voice commands are used to control the electrical appliances.

4) Gives review of home automation system for disabled people using brain computer interface .this research includes control and monitoring home appliances from graphical interface using brain- computer interface that use an input source and being control wirelessly.

5) proposes a home appliances controlling system through spoken commands using handheld devices and ZigBee module. This system uses voice commands and SMS commands to control the appliances. When the voice commands are given then it is converted to text message and sent through GSM. ZigBee module is used to control multiple points at a time. 
6) gives the study about home automation systems. This paper tells about the different technology used for the home automation systems like GSM, ZigBee, Bluetooth and other technologies.

7) presents a home automation and security system using Android Accessory Development Kit. All the appliances are connected to the ADK board and communication is established between ADK and Android mobile. Authentication is also installed in accessing the appliances.

8) gives Bluetooth based home automation and security system using ARM9 . Electrical appliances are controlled using ARM7 and ARM9 board. At the transmitting end ARM9 is used with Bluetooth dongle and ARM7 is used in receiving end which connected to appliances through driver circuit.

9) describes different network technologies for remote-controlled home automation systems. This shows the useful ness of remote-controlled home automation systems in domotics, illustrate different ways to control of a home network using standardized technologies, issues that affects the remote-controlled home automation systems.

10) authors have proposed design and implementation of voice controlled wireless intelligent home automation system based on zigbee.in this system different types of inputs are given like voice, text and direct input from the user to control the different appliances through relay circuit and buzzer is used for alerting system.

11) presents home automation system using Bluetooth and android application. Low voltage activating switches are used in input side. It send the control signal to the controller board which PIC Microcontroller here. Controller switches the appliances according to the given input device and controller sends the status of the appliances to GUIs.

12) proposes health care in home automation systems with speech recognition and mobile technology. This system includes developing system with speech recognition, speech synthesis, face recognition, controls for Arduino hardware a and smart application for remote controller.

13) presents home automation using ZigBee technology. Voice commands are converted by HM2007 board and then given to controller board. The controller board send the controlling commands to different devices through ZigBee module. ZigBee modules are used at both sending and receiving end

\section{PROPOSED MODEL}

The block diagram of proposed model is as shown in figure 1. The model consist of a main controller board Intel Galileo with wireless Centrino board for internet connectivity.

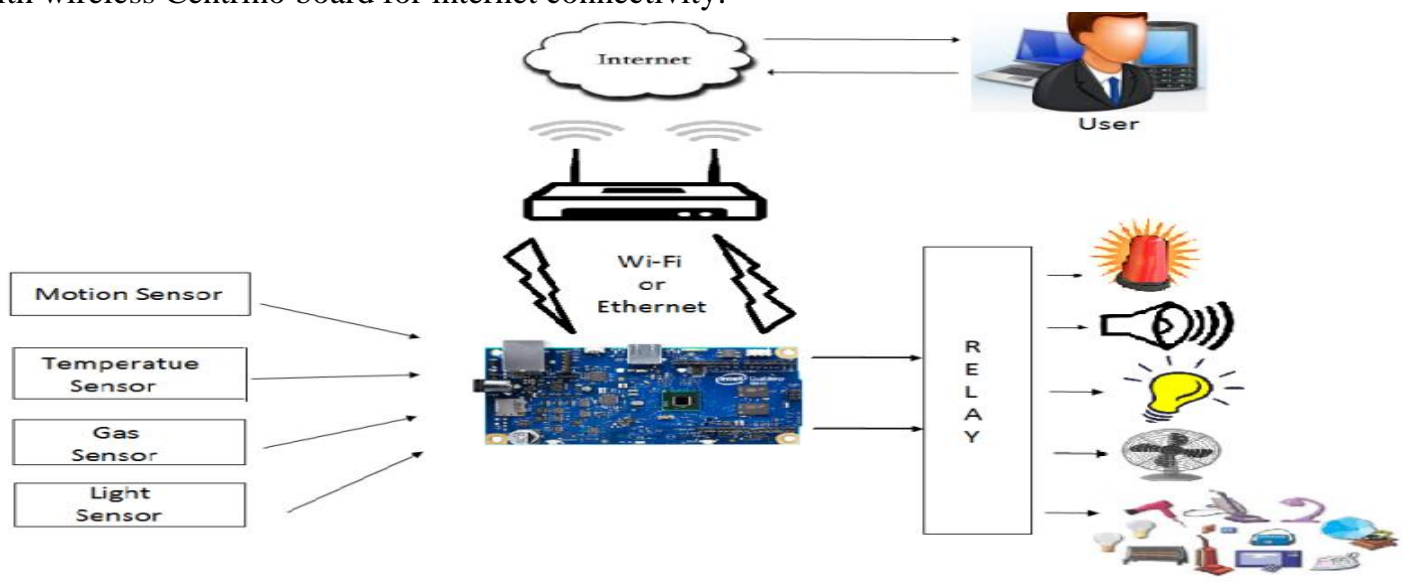

Figure 1: Block diagram of proposed model.

Different type of sensors are adopted, to monitor various characteristics, like motion sensor to detect suspicious movement by persons either inside or outside the house, temperature sensor to detect variation in temperature, light detection sensor to identify changes in brightness inside the house, gas sensor to identify any gas leakage and fire/smoke sensor for smoke detection. For alerting people a buzzer and a red light is used. Different electrical appliances are connected through relay and controlled remotely.

When the value of sensors exceeds the threshold level then it should activate the alerting system. For example turning on the fan when temperature rises above threshold level, switching on the light when brightness goes below the threshold. The buzzer and red light alerting system will be activated for some situations like gas detection, fire detection and motion detection. The microcontroller is connected to the internet through Wi-Fi board. The user is able to monitor the status of the house from anywhere any time using internet connective device. A unique and universal IP address is assigned to the microcontroller. By entering that IP address in the browser user can monitor the house. User can also change the status of the appliances like turning on/off of light, fan etc. remotely. 


\section{SYSTEM OPERATION}

The basic system operation of proposed model is shown in figures $2 \& 3$. Figure 2 is the flow chart of the operation at the controller end. When the controller board is turned on, the board will establish connection to the internet if the connection fails and it will try again to connect. If connection is established then the controller gathers the sensor data from all the sensors in the house. Then the data is sent to the user through internet. When the controller reads the sensor data it will compare it with the preset threshold value. If the value is greater/lower than the threshold value then the user is alerted and the actuation carried out. At the same time, the controller also waits and receives the user commands to activate and actuate the system as per the user command like turning on and off of the electrical appliances

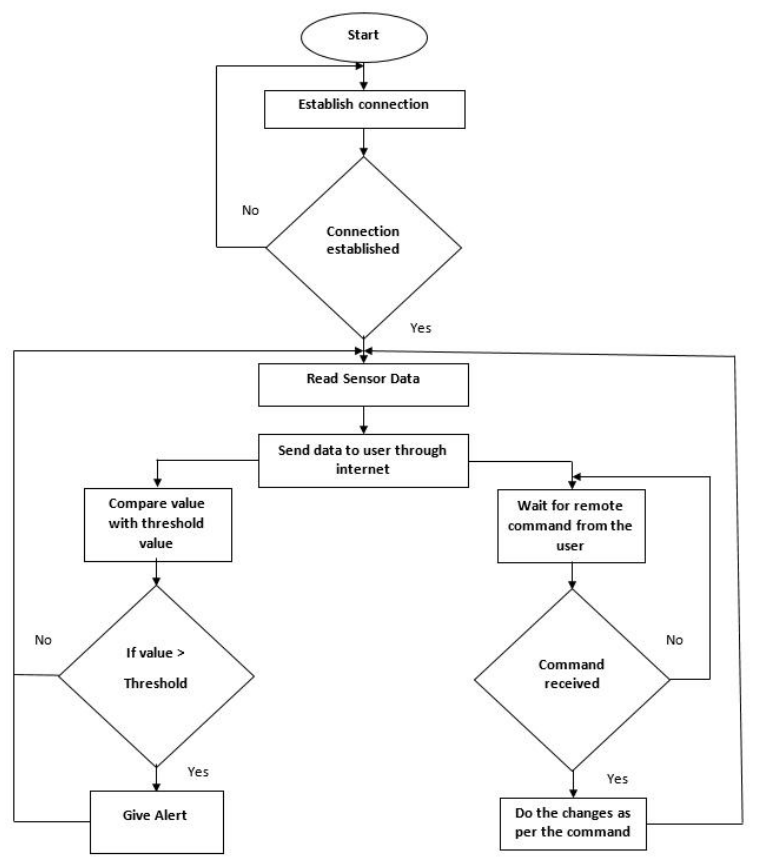

Figure 2: Basic system operation.

Figure 3 shows the operation at the user end. When the user wants to check the status of the house, user will have to initially enter the IP address which is assigned to the board. Then a window will ask for a password to enter the monitoring system. If the entered password is correct then a window shows the status of the house and a list of devices. Then the user have to select the device if he wants to change the status of the device. Then the command is sent from the end user device to controller through the internet. Then command is executed at the controller.

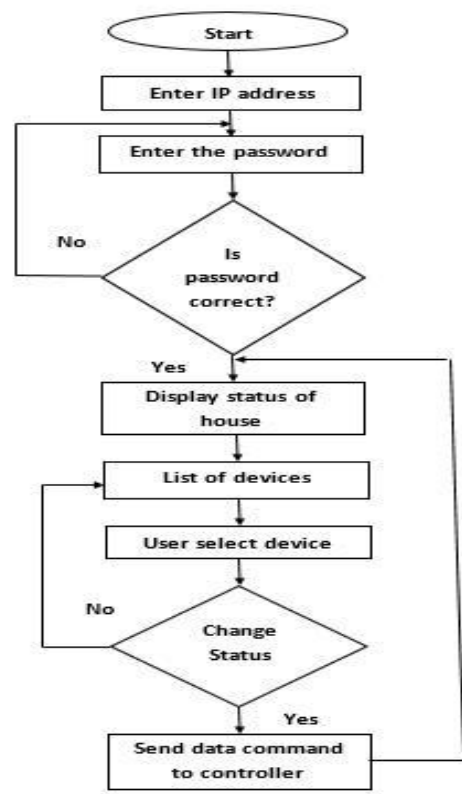

Figure 1: Operation at the user end. 
Vol. 4, Special Issue 2, April 2016

\section{CONCLUSION}

This paper presents a smart home monitoring and alerting system for the disabled. The proposed system incorporates several sensors like temperature sensor, motion detector, light detector, gas detector, and fire detector. The system uses internet for communication between the end user and embedded board. Using this type of system, end users can monitor home remotely through mobile, I-Pod, Tablets, computers and other devices which have internet connectivity. Users can be aware of their home Status/condition and can take care of disabled persons from anywhere and at any time.

\section{ACKNOWLEDGMENT}

The author expresses deepest gratitude to NMAMIT Nitte \& Visvesvaraya Technological University for all the encouragement and support.

\section{REFERENCES}

[1]. Bilal Ghazal and Khaled Al-Khatib, "Smart Home Automation System for Elderly, and Handicapped People using XBee," Phil. Trans. Roy. Soc. London, vol. A247, pp. 529-551, April 1955.

[2]. Basma M. Mohammad El-Basioni1, Sherine Mohamed Abd El-Kader2, and Hussein S. Eissa3, "Independent living person with disabilities and elderly people using smart home technology" International Journal of Application or Innovation in Engineering \& Management (IJAIEM)

[3]. Thoraya Obaid, Haliemah Rashed, Ali Abu El Nour, Muhammad Rehan, Mussab Muhammad Saleh, and Mohammed Tarique "Zigbee based voice controlled wireless smart home system" International Journal of Wireless \& Mobile Networks (IJWMN) Vol. 6, No. 1, February 2014.

[4]. S.P.Pande, Prof.Pravin Sen "Review On: Home Automation System For Disabled People Using BCI", IOSR Journal of Computer Science (IOSRJCE) e-ISSN: 2278-0661, p-ISSN: 2278-8727 PP 76-80

[5]. Faisal Baig, Saira Beg and Muhammad Fahad Khan Elissa, "Zigbee Based Home Appliances Controlling Through Spoken commands Using Handheld Devices" International Journal of Smart Home Vol. 7, No. 1, January, 2013

[6]. Sathish Palanaippan,Naveen Hariharan,Naren T Kesh,Vidhyalakshmi S,Angel Deborah S, "Home Automation Systems-A Study" International journal of computer Applications(0975-8887)Volume 116- No.11,April 2015

[7]. Deepali Javale,Mohd.Mohsin,Shreerang Nandanwar, Mayur Shingate, "Home Automation abd security System Using Android ADK" International journal of Electronics Communication and Computer Technology (IJECCT) Volume 3 Issue 2(March 2013).

[8]. D.Naresh,B.Chakradhar,S.Krishnaveni "Blueetooth Based Home Automation and Security System Using ARM9" International Jornual of Engineering trends and technology(IJETT)-volume4 issue 9-sep 2013.

[9]. Armando Roy Delgado, Rich Picking and Vic Grout, "Remote-controlled home automation system with different network zteechnology", centre for Application internet research(CAIR), university of Wales,NEWI,Wrexham,UK.

[10]. Mitali patil,Ashwini Bedare,Varsha Pacharne, "The design and implementation of voice controlled wireless intelligent home automation system based on zigbee".International journal of advance research in computer science and software Engineering.

[11]. R.A.Ramlee, M.H.Leong, R.S.S.Singh, M.M.Ismail, M.A.Othaman, H.A.Sulaiman, M.H.Misran, M.A.Meor Said, "Bluetooth remote home automation system Using Android Application", The international journal of Engineering and science, Volume 2 issue 01,pages 149-153,2013.

[12]. Jasmin kurta,Gunay Karh ,"health care in home automation system with speech Recognition and mobile Technology", American journal of engineering research(AJER) e-ISSN:2320-0847 p- ISSN:2320-0936,Volume-03, issue-05, pp-262-265.

[13]. S.Benjamin Arul, "Wireless home automation system using zigbee", international journal of engineering and science research volume 5, issue 12, December-2014 